\title{
The Application Research on the Teaching Mode of Flipped Classroom under the Background of "Internet Plus"
}

-----“"Vocational General Basic Skills Training” Course as the Example

\author{
Liu $\mathrm{Yi}^{1, \mathrm{a}}$ \\ ${ }^{1}$ Nanchang Institute of Science and Technology, Nanchang 330108, China
}

aliuyinc@126.com

Keywords: Internet plus; model of teaching; flipped classroom

\begin{abstract}
In the era of "Internet plus", with the significant changes have taken place in education field, a lot of new teaching methods and teaching models have been proposed. These changes are verifying the intimate connection between the vocational education and network, it is restructuring all kinds of teaching resources, and innovate the technical education mode. It is the calls of the times, is the mission of vocational education of people. By analyzing the practical teaching system of vocational general basic skills training, and thinking the omni-directional teaching management mechanism, we formulate a set of new teaching mode for the flipped classroom.
\end{abstract}

\section{Introduction}

Vocational basic skills is the basis of the profession, the core ability is tall buildings based on vocational basic skills. In recent years, many enterprises reflect that there are differences in ability between the recruiting students and the expectations of enterprises. Some graduates are not solid in basic skills, their operation is not standard, and lack the ability to work independently. It brings great influence to the production efficiency of enterprises, and it brings negative influence to the development of vocational colleges either. So vocational education must strengthen the students' vocational basic skills training, and promote the vocational ability of them.

At the same time, under the impact of new technology, new ideas and new model, like cloud computing, big data and flipped classroom, informational education has been a rapid development in the global scope.

The emergence of "Internet plus" deeply integrated the innovation of the Internet with the economic society in various fields, promoted the technological progress, the improvement of efficiency and the organizational change, and it also promoted the innovation and productivity of real economy. Our education concept, teaching methods and training mode have deeply changed by the integration of the Internet and education. The updates of education content, the changes of teaching mode, and the diversity of education evaluation make the education in China is entering a great revolution. Khan academy and TED education speech lesson have made "micro classroom" become familiar to people as an informal approach to learning,

Under such a background, the traditional teaching method has already can't keep up with the development of the "Internet plus", the vivid flipped classroom, the network classroom can login at any time and other major changes is closely linked together with the vocational education.

\section{Flipped Classroom}

Flipped classroom teaching pattern is a teach method which relatively advanced in recent years [3], is known as an important technology changes affect the classroom teaching in 21 century. The most obvious feature of the classroom is "learning knowledge after class, digesting knowledge in class", turning the traditional classroom teaching mode, segmenting the time of theory study and practice 
study. It mainly uses students' autonomous to learn knowledge after class, digesting, consolidating and absorbing in class.

Flipped classroom was originally proposed by the two old high school teacher Jon Bergmann and Aaron Sams. They create video, students learn video after class, and in the classroom students practice to learn with each other and master the concept. [4].Due to flipped classroom greatly improve the efficiency of the classroom, promote the students' comprehensive ability of ascension, and adapt to both the social development and the application of new technologies at the same time, therefore it was quickly spread to open. Later, a Harvard professor, Eric Mazur further integrate flipped classroom with peers teaching method, students prepare before class by watching video, reading articles or relocate their thinking to the original knowledge, teachers comb summary for all kinds of problems; students propose problems in the class, the teacher and student solve the problems by mutual collaboration. Other famous case like the khan academy, which using the popular flipped video and class teaching practice system of classroom practice, and Stanford university puts forward the common learning mode combined with flipped classroom, etc.

At present, our country already has many professional teaching video network stations. Moreover, Net Ease's open classes and micro class network also have accumulated rich teaching video, which provides a rich material for the revolution of flipped classroom. Several provinces such as Beijing, Shanghai has made a meaningful exploration for flipped classroom, for example Chongqing JuKui, shenzhen nanshan experiment science school, as well as guangzhou tianhe with the practice of "vitreous project", etc., which carry out flipped classroom teaching reform has made a preliminary into effect.

It is significant for the integration of flipped classroom and vocational general basic skills training. The courses represented by "vocational general basic skills training" demand the students master the actual operated ability, it is difficult to help students truly understand the specific operation process and application of actual projects if only rely on the teachers' teaching in the classroom. Using reverse course Class teaching. It can promote students' active learning after class, let students devote to the general basic skills training through the class discussion between teachers and students, by using flipped classroom, which make up for the deficiency of the traditional classroom teaching, and improve the teaching efficiency.

\section{The Teaching Problem of Flipped Classroom}

First of all, teachers did not change the teaching idea. In the influence of the traditional teaching mode, most domestic colleges and universities insist on the mode of "teacher as dominant, multimedia as auxiliary". Centralized knowledge is taught in the classroom, and teachers usually teach students with their short memory to grasp knowledge, lack of autonomy in the review after class, the learning effect is not obvious. To realize flipped classroom teaching, the key factor is the teacher must have advanced scientific concept, create follow different courses focus on the teaching content, and to adapt to the students of micro video resources in particular.

And then, students lack the ability of autonomous learning. In the traditional classroom teaching in colleges and universities, the teacher limited time on class teaching and pay a little attention to student's extracurricular learning. It is easy to lack of testing standard in this way, and most of the students rely on teachers teaching in the classroom, seldom autonomous learning after class. However, guiding the students to do a good job in preparation before class is the foundation of the flipped classroom teaching mode. Students have appropriate network hardware equipment, to collect online learning resources; Management of colleges and universities must make use of network platform for online overseers, and test students' autonomous learning situation. For students who have not been well prepared before class, they can be added motivation and urge through the network platform, and combined with course grades at the same time, to ensure that the majority of students on effectiveness of preparation before class, then turn to promote the smooth completion of classroom teaching. 


\section{The Teaching Mode of Flipped Classroom under the Background of "Internet Plus"}

Usually, the vocational college students' vocational skills training include:

1) The general basic skills training

Including computer application ability, foreign language application ability, putonghua level, etc.

2) Professional basic skills

Professional basic skills refers to the professional in the field of basic skills. Teachers are be requested to guide in practice, pay attention to the standardization of the skills training and skills assessment scientifically, cultivate students' thinking and the ability to work and analysis problems independently.

3) Professional skills training

This practice is usually according to the teaching progress and teaching requirements, arrange students to off-campus practice base for training or simulation practice at school. Professional skill training should have a clear inspection standards, enterprise field personnel can be hired to be teachers.

4) The comprehensive professional ability training

By organizing the student to participate in professional skills contest, relevant professional skill level or professional qualification certificate examination, to improve students' comprehensive vocational ability.

Flipped classroom depends on the teaching video which is prepared for the implementation of flipped classroom. Teacher recorded lesson, for instance to explain the teaching content, and describe how the various operations around a comprehensive program, since each video control within 15 minutes as far as possible, it needs to be taught to understand the interpretation, strongly practical, and has certain typical examples and the basic operation. It should be uploaded to the cloud disk of class, for students to preview before class.

In flipped classroom teaching, teacher's role has shifted from the content of present coach for learning. Teachers should guide discusses knowledge, optimize the structure of the students' knowledge, improve students' ability of independent thinking and problem-solving. Teachers only with good ability for course creation and classroom management, can fully reflects the students' main body role in class teaching, build autonomous learning atmosphere, and improve students' exploring and innovating ability.

At the same time, students can arrange their own learning according to their circumstance. Students completely can watch video of the teacher in their leisure time with a relaxed atmosphere. It will not be nervous for worry about missing something, or can not keep up with the teaching rhythm because of distractions. Learning is controlled in our own hands, we can stop to think or note carefully when encounter problems, we also can look for your teacher and classmates for help through the chat software.

Students' duty is not only complete the operation of the teacher in class step by step, teachers need arrange the task of expanding at the last part of the each video. Students need choose the task to complete according to their own strengths, and improve their ability of independent thinking and hands-on practice.

\subsection{Requirements analysis}

Requirements analysis includes two parts: students' analysis, and content analysis. Students is the main body of flipped classroom teaching, through the analysis of the students can grasp the students' individual differences such as interest, learning habits and learning effect, both professional characteristics, and as the important basis for selection and production of video. Content analysis is the weight of the weight, not all content is fit for flipped classroom teaching, it should select suitable knowledge point into a line of video according to the teaching outline. The learning capacity points, difficulty and doubt should be chosen generally.

\subsection{Process design}

Including preparation before class, classroom practice, and summed up after class

Preparation before class need to be taught by both teachers and students to complete. First, the 
teachers make proper learning video as short as possible according to the demand analysis before class. At the same time, teachers should design some interesting question, guide students to active thinking, stimulate students' interest in learning; And then, teachers upload the video and problems to the network teaching platforms, download learning independently by students; Students download to watch the video and clear about the learning tasks, and study in their own time arrangement, learning style. If have any doubt in study, students can communication with teachers online.

According to the problems which students' feedback preparation before class, classroom practice should give an interpretation of instructions. And then demonstrate a simple project, talk about project evaluation standards, divide project into small groups, and design the corresponding questions to guide students to carry out the project practice. Problems encountered in the project development, can be discussed with classmates and teachers. After the completion of the project development, teachers organize students to communicate project with demonstration and evaluation.

Summed up after class is very necessary. First of all, teachers should prepare related assignments for students according to the situation of students' preparation before class and classroom practice. And then, it is necessary to furtherly communicate with students, and give timely guidance reply. Finally, and the most crucial step, teachers must evaluate the students' performance. Because of the trouble with the flipped classroom teaching methods is how to ensure that students must prepare carefully before class, the students of the class must be effective assessment to encourage their learning, and otherwise there is no guarantee about the teaching effect.

\subsection{Evaluation}

Flipped classroom teaching mode is adopted to improve the reform, it is necessary to establish a set of perfect performance appraisal system, in order to improve the teaching quality. Due to flipped classroom teaching mode pay attention to the preparation before class and classroom practice, and so on students' evaluation also need to consider students' preparation before class and classroom practice, establish a quantifiable indicators of evaluation system, thus give an objective and fair evaluation to student's learning process and the results.

\subsection{Conclusion}

Through effective summary analysis, it is benefit to develop the students' ability of self-reflection, spur the students' autonomous learning, and improve their independent to study. Through teaching reflection, teachers can upgrade the teaching plan, help to develop the deep courses, and enrich the teaching experience. For students, students can summarize in view of the learned knowledge, and then communicate with each other to share the experience. By exchanging learning experience, the students can share the results of autonomous learning. For example, by showing work, communication and interaction between the oral practice. Throughout the learning process, students are the main body of learning, the teacher must carry on the effective coordination and guidance, to help students explore independently, but also guide the student self-reflection summarized, make up for the shortage, combined with the students' learning through incentive evaluation, persistent learning and encourage students, improve the ability of the student to obtain knowledge, promote the students' ability of using knowledge comprehensively.

\section{Summary}

By the experiment of flipped classroom, we found that students have greatly improved in learning initiative than before, the proportion of students who positive prepared before class have increased, and the efficiency of classroom lectures also had a big rise. Students listened carefully in class with interest and problems, the problems didn't be solved before the class were able to be solved under the guidance of the teacher, the grades also naturally have been greatly improved with such kind of happiness beyond words to overcome the difficulty. In addition, it enhanced the feelings between the classmates, let students experience the power of the team by the team project of flipped classroom.

In short, in the era of "Internet plus", flipped classroom will not only satisfy the personalized learning needs of learners, but also really do it according to their students' aptitude, as well as effectively improve the teaching efficiency. By using Internet technology and Internet thinking to 
think and solve the problems in the field of education, it has changed the traditional forms of teaching and learning, and brings us a new experience.

\section{Acknowledgements}

Subject of teaching reform of Nanchang Engineering College: The Application Research on the Teaching Mode of Flipped Classroom under the Background of "Internet Plus"------."Vocational General Basic Skills Training” Course as the Example, Project number: NGJG-16-5.

\section{References}

[1] Lage M J, Platt G J, Treglia M. Inverting the Classroom: A Gateway to Creating an Inclusive Learning Environment [J]. The Journal of Economic Education, 2000, 31(1):30-43.

[2] Frydenberg M. Flipping excel [J]. Information Systems Education Journal, 2013, 11(1).

[3] Clifton C, Boutell M. SPLICE: Self-Paced Learning in an Inverted Classroom Environment [J]. Rose, 2012.

[4] THEO HUG. Micro learning and narration [R].Fourth Media in Transition conference: The Work of Stories, 2005.5.

[5] The flipping classroom [DB/OL]. (2012-12-1). [2014-4-10].

http://educationnext.org/the flipping classroom.html. 